\title{
Relato de caso - privação sensorial de estímulos e comportamentos autísticos
}

\section{Case report - deprivation of sensory stimuli and autistic behaviors}

\author{
Ana Cristina de Castro Coelho ${ }^{1}$, Elisa Pinhata Iemma ${ }^{2}$, Simone Aparecida Lopes-Herrera ${ }^{3}$
}

\begin{abstract}
RESUMO
O objetivo deste trabalho foi relatar o caso de uma criança que apresenta características autísticas e sofreu privação de estímulos por negligência materna. O acompanhamento da criança foi feito pela equipe da Clínica de Fonoaudiologia da Faculdade de Odontologia de Bauru (FOB-USP). A criança era do gênero masculino e tinha dois anos e 10 meses, na época da avaliação fonoaudiológica. O diagnóstico foi distúrbio de linguagem como parte de um transtorno global do desenvolvimento e foi indicada terapia fonoaudiológica. Devido a características de comprometimento do desenvolvimento global e nutricional, a criança também foi encaminhada a uma instituição especializada em autismo e a atendimento médico. Com o início da terapia fonoaudiológica, a criança apresentou aumento de contato ocular, aceitação de contato corporal, maior interesse pelos objetos, iniciação de vocalizações e diminuição dos movimentos repetitivos; porém, o resultado terapêutico foi comprometido devido à problemática envolvida. Todo o trabalho foi realizado em conjunto com as creches que a criança freqüentou e com os órgãos assistenciais relevantes, já que foi feita uma denúncia formal da negligência materna. O intuito deste relato de caso é demonstrar que, em casos graves como este, é necessária uma intervenção global, com a atuação de diversos profissionais da saúde, a fim de proporcionar o desenvolvimento em todos os aspectos comprometidos. O apoio da família é fator determinante no desenvolvimento da criança e, por isso, não se sabe até que ponto a manutenção das características autísticas e os comportamentos apresentados pela criança estão sendo determinados pela privação sensorial que esta sofre ou pela severidade do quadro autístico em si, devendo o trabalho de investigação e de intervenção ter continuidade.
\end{abstract}

Descritores: Transtorno autístico; Privação sensorial; Maus-tratos infantis; Transtornos do desenvolvimento da linguagem

\section{INTRODUÇÃO}

O desenvolvimento da linguagem se dá durante os primeiros anos de vida e a própria linguagem em si, em todos os seus aspectos, acompanha praticamente todas as atividades do ser humano ao longo de sua vida. $\mathrm{O}$ fato da aquisição da linguagem não requerer esforço especial pode parecer uma observação trivial, mas é bem verdade que, em toda criança que vive em condições normais, tal aquisição é esperada. Este aspecto natural da linguagem é questionado quando a criança

Estudo de caso realizado na Clínica de Fonoaudiologia da Faculdade de Odontologia de Bauru da Universidade de São Paulo - USP - Bauru (SP), Brasil. (1) Especializanda pelo Centro de Estudos da Voz - CEV - São Paulo (SP), Brasil; Aluna do Programa de Prática Profissionalizante da Faculdade de Odontologia de Bauru da Universidade de São Paulo - USP - Bauru (SP), Brasil.

(2) Mestranda do Programa de Pós-graduação em Educação Especial da Universidade Federal de São Carlos - UFSCar - São Carlos (SP), Brasil.

(3) Professora Doutora do Departamento de Fonoaudiologia da Faculdade de Odontologia de Bauru da Universidade de São Paulo - USP - Bauru (SP), Brasil.

Endereço para correspondência: Simone Aparecida Lopes-Herrera. Al. Octávio Pinheiro Brisolla, 6-65/91, Vila Universitária, Bauru - SP, CEP 17012-059. E-mail: lopesimone@usp.br

Recebido em: 1/3/2007; Aprovado em: 24/10/2007 demora a falar. Quando se refere ao período pré-lingüístico do desenvolvimento, o que pode surpreender e sobre o que se questiona é, por um lado, a maneira quase perfeita como a mãe e a criança se compreendem e, por outro, a eficácia com que a criança, desde os primeiros meses de vida, transmite informações sobre seus estados fisiológicos, afetivos e cognitivos. A linguagem virá enxertar-se progressivamente nesta comunicação precoce, eficaz e segura; enfim, quando a criança começa a utilizar as primeiras expressões que podem ser consideradas como palavras, ela já adquiriu um domínio incontestável da comunicação(1).

A capacidade da criança para o aprendizado da linguagem pode não ser constante e pode se deteriorar com a idade. Uma consequiência disto é que, se algum fator interferir na aquisição da linguagem durante os cruciais primeiros anos é possível não se recuperar posteriormente o déficit de linguagem, mesmo que o fator causador deste seja retirado. Não são todas as condições que afetam a evolução da linguagem, tendo efeitos permanentes e vitalícios, mas certas condições podem durar o suficiente para impedir que certos estágios do desenvolvimento se manifestem. Portanto, eventos adversos nos primeiros anos de vida podem provocar a regressão ou a paralisação do desenvolvimento da linguagem, sendo esta uma condição não muito comum em relatos da área ${ }^{(2)}$. 
Pode-se dizer que a interação entre pais e criança será afetada nos casos de deficiência de linguagem. Pais de crianças com deficiência de linguagem são muito menos compreensivos e muito mais críticos do que os pais de crianças com desenvolvimento normal da linguagem. As mães de crianças com deficiência de linguagem satisfazem as necessidades físicas das crianças, mas convivem com elas de uma forma paralela, em vez de integrar-se ativamente com elas. As evidências sugerem que a conseqüiente distorção da interação em casos menos acentuados também pode ocorrer mais em função das necessidades da criança e das dificuldades dos pais em tentar corresponder a tais necessidades do que um estilo particular de fala que os pais possam usar ${ }^{(3)}$.

O surgimento da linguagem marca o desenvolvimento cognitivo e social da infância. Embora a criança em desenvolvimento típico não fale durante o primeiro ano de vida, sua interação com outros é fundamental para o desenvolvimento da linguagem; embora o repertório de linguagem expressiva do bebê seja limitado, seus pais percebem rapidamente a variação nos padrões de choro, vocalização e no padrão de balbucio, conforme a situação e acompanham com satisfação o surgimento de gestos e combinações de gestos e sons ${ }^{(4)}$.

O desenvolvimento da criança é resultante da interação entre suas capacidades potenciais e a influência de seu ambiente. Uma insuficiência de estimulações sensoriais, afetivas e sociais tem como conseqüência um atraso do desenvolvimento das esferas cognitiva, afetiva e relacional. A linguagem é um dos aspectos do desenvolvimento da criança sobre o qual pesam, especialmente, as carências do ambiente. Tais carências podem obstaculizar o desenvolvimento da linguagem e, quando severas, podem impedir até a sua aquisição. Um exemplo desta situação extrema é fornecido pelo caso das crianças selvagens que cresceram afastadas de qualquer contato humano. É possível questionar se algumas das crianças selvagens encontradas eram normais, quando foram abandonadas ou se uma patologia autística ou um atraso profundo não estavam, na verdade, na origem dos maus tratos e do abandono ${ }^{(5)}$.

Existem relatos de casos de sujeitos que sofreram privações extremas na primeira infância e sua repercussão no desenvolvimento da linguagem. Algumas características apresentadas por essas pessoas são a carência de atributos humanos básicos como a fala e habilidades sociais. Em estudos de casos de crianças desnutridas, as evidências para se fazer uma correlação direta entre a desnutrição e o desenvolvimento da linguagem são vagas. Devem ser levadas em consideração questões como a severidade da desnutrição e os constituintes dietéticos afetados, os déficits cognitivos resultantes, se a linguagem está afetada mais ou menos severamente do que outros aspectos da competência mental e o contexto social, ou seja, deve-se considerar a natureza do ambiente onde a criança desnutrida é criada ${ }^{(6)}$.

Um estudo ${ }^{(7)}$ constatou que o atraso do desenvolvimento da linguagem foi o problema mais comum encontrado por fonoaudiólogos que atenderam casos com vítimas de maus tratos, dentre eles abandono/negligência. A negligência é uma situação na qual não há uma interação satisfatória entre mãe e filho durante uma fase crítica da vida da criança. Essa ocorrência caracteriza uma das condições capazes de inter- ferir no desenvolvimento infantil. Para o autor, dependendo da dimensão psicológica e neurológica dessa negligência, os danos podem ser permanentes. Há outros estudos ${ }^{(6,8)}$ sobre abandono em fases precoces do desenvolvimento infantil, que demonstram prejuízos no desenvolvimento físico e psíquico das crianças vitimadas, como a perda gradual de interesse pelo meio e comportamentos estereotipados.

Os processos de desenvolvimento da linguagem são controlados por um programador genético que evolui para garantir o sucesso, no sentido de adquirir o poder para comunicar-se sob uma extensa, porém limitada série de circunstâncias ambientais, sendo que um dos achados confirmadores foi feito por estudos realizados com crianças negligenciadas com privações extremas. Os achados de pesquisas encontradas na literatura, realizadas com crianças que sofreram privação sensorial, levantaram importantes questões com respeito à plasticidade do potencial de habilidade mental diante de um ambiente extremamente adverso e de como se daria o desenvolvimento da comunicação e linguagem. Nestas condições, a criança que sofre privações sensoriais na primeira infância pode vir a apresentar inúmeros comportamentos autísticos ${ }^{(6)}$.

$\mathrm{O}$ autismo é considerado uma síndrome comportamental com etiologias múltiplas e curso de um distúrbio do desenvolvimento, sendo caracterizado sucintamente por déficit de interação social, visualizado pela inabilidade de relacionar-se com o outro, usualmente combinado com déficit de linguagem e alterações de comportamento ${ }^{(4)}$.

A idéia de autismo como uma desordem específica foi proposta por Kanner, para identificar um reduzido grupo de crianças pequenas com sérios prejuízos em seus comportamentos sociais e de comunicação. Em abordagem eminentemente descritiva, a Associação Americana de Psiquiatria ${ }^{(9)}$ enumerou um complexo conjunto de inabilidades, as quais afetam a comunicação, a capacidade cognitiva e a interação social de indivíduos, com grande variedade de combinação e intensidade de comprometimentos e propôs a classificação desses quadros como transtornos globais do desenvolvimento. Uma das chaves do diagnóstico de transtorno autista é o prejuízo qualitativo na comunicação. Por definição, indivíduos com autismo mostram desvios na aquisição da linguagem, que variam de uma ausência de comunicação funcional a um conhecimento lingüístico adequado, porém com inabilidades no uso desse conhecimento para a conversação ou para outro contexto no discurso ${ }^{(10)}$.

O autismo possui ainda características de isolamento e de insistência na repetição do comportamento, as quais indicam falhas em estabelecer relacionamentos e desenvolver a linguagem $^{(11)}$. Pode se manifestar no bebê desde as primeiras semanas de vida ou aparecer apenas na primeira infância ou na idade pré-escolar, caracterizando-se então por perda da linguagem, da capacidade de socialização, das condutas de jogo e das habilidades cognitivas. As crianças que apresentam autismo severo manifestam pouco interesse pelas interações sociais. As crianças menos severamente atingidas podem ser afetuosas, mas ao seu modo, isto é, com apenas algumas pessoas, ou ainda com qualquer pessoa e de maneira inapropriada ${ }^{(12)}$.

A noção de autismo tem sofrido uma série de mudanças ao longo do tempo. Sua definição e, concomitantemente, seu diagnóstico têm variado a partir da busca de uma maior 
elaboração conceitual, fruto do grande aumento de pesquisas na área ${ }^{(13)}$. As dificuldades de comunicação são um elemento importante para a identificação precoce dos distúrbios do espectro autístico ${ }^{(14)}$.

Considerando o autismo um distúrbio neurológico, este pode se mostrar como conseqüência de perturbações ainda não especificadas no desenvolvimento do cérebro durante sua maturação. Nestes casos, o autismo é conseqüência de uma encefalopatia não-progressiva, de origem pré-natal, que terá conseqüências ao longo da existência do indivíduo, ainda que suas manifestações mudem consideravelmente com a idade. $\mathrm{O}$ nível intelectual não é um dos critérios de definição do transtorno autista, mas, na maioria dos casos, é baixo. As etiologias que puderam ser reconhecidas nestes casos são variadas. Assim, não se pode fugir à conclusão de que é exatamente a disfunção de um sistema ainda não definido que determina o aparecimento de sintomas autísticos e não a própria etiologia ${ }^{(13)}$.

$\mathrm{O}$ autismo pode ser ainda definido como uma síndrome comportamental, já que não há nenhum teste neurológico, neuropsicológico ou de linguagem que possa ser utilizado para confirmar ou invalidar seu diagnóstico. Este se baseia inteiramente na avaliação de comportamentos como a sociabilidade, o jogo e a afetividade. Tal avaliação provém da observação clínica e da investigação do meio familiar da criança; ela deverá incidir sobre as manifestações comportamentais que puderam ser observadas desde o início do desenvolvimento ${ }^{(12)}$.

A abordagem terapêutica das alterações de linguagem associadas aos quadros de autismo infantil tem sido objeto de estudo há varias décadas, pois essas alterações são descritas como um dos elementos fundamentais de tais quadros clínicos, independentemente da perspectiva pela qual eles sejam abordados ${ }^{(13)}$. Uma das funções do fonoaudiólogo na atuação com crianças do espectro autístico é a identificação dos aspectos para os quais a criança mostra mais habilidades para que estes sejam utilizados como apoio nas atividades escolares e em abordagens terapêuticas de comunicação e linguagem. Deve-se enfatizar a necessidade de flexibilidade e adaptação às necessidades e às mudanças por parte dos terapeutas.

Embora as dificuldades de interação social, de comunicação verbal e os padrões de comportamento restritos e repetitivos sejam comuns a todos os transtornos do espectro autístico, existem diferenças fundamentais entre eles, relacionados a fatores como etiologia, idade de manifestação, característica regressiva ou de desenvolvimento, diagnóstico, funcionamento intelectual, perfil neuropsicológico e prognóstico. Essas variáveis determinam diferentes possibilidades de abordagens terapêuticas e educacionais, baseadas nas principais falhas e nos estilos preferenciais de aprendizagem, sendo este o principal argumento contra um único modelo de intervenção ${ }^{(13)}$.

Tendo em vista as considerações realizadas até aqui, o objetivo deste trabalho foi realizar um relato de caso de uma criança que sofre privações sensoriais por negligência materna e que apresenta características autísticas.

\section{APRESENTAÇÃO DO CASO CLÍNICO}

A criança, alvo do presente estudo, é do gênero masculino, apresentando dois anos e dez meses quando compareceu pela primeira vez à Clínica de Fonoaudiologia da Faculdade de Odontologia de Bauru (FOB-USP). Foi assinado o termo de consentimento livre e esclarecido, de acordo com as normas da Clínica de Fonoaudiologia, no que se refere à utilização do caso para fins científicos, segundo Resolução 196/96 do CONEP (Comissão Nacional de Ética em Pesquisa). Todos os procedimentos deste estudo foram submetidos à Comissão de Ética em Pesquisa (CEP) da Faculdade de Odontologia de Bauru (FOB-USP), da Universidade de São Paulo e aprovados sob protocolo $n^{\circ}$ 131/2006.

No primeiro atendimento realizado, a criança chegou acompanhada por sua babá (cuidadora) e a assistente social da creche que freqüentava. No primeiro momento, não foi realizada uma anamnese formal, pela ausência da mãe, que não compareceu à clínica. A queixa inicial pela qual a criança foi encaminhada pela creche que frequientava a clínica de fonoaudiologia era de que havia suspeita de problemas auditivos, uma vez que a criança não respondia a estímulos. Segundo a assistente social da creche freqüentada pela criança, na época da queixa e da cuidadora (babá), a referida criança sofria de privações sensoriais de estímulos por negligência materna e apresentava características autísticas.

Não foi possível realizar a avaliação audiológica devido ao comportamento da criança, que não quis sair do carrinho, chorando quando alguém tentava pegá-la e não aceitando toques. Dentro do carrinho, a criança apresentou movimentos repetitivos corporais e com a chupeta, com ausência de contato ocular. Foi observado que ele era muito magro e pequeno para a idade (aparência de bebê de um ano, aproximadamente) e não apresentou nenhum comportamento comunicativo. $\mathrm{Na}$ tentativa de uma avaliação comportamental de audição, não foi possível aplicar o teste de sons de Ling devido ao comportamento apresentado. Entretanto, localizou o som do seu nome, somente quando a babá chamou-lhe, não respondendo para outras vozes.

A babá e a assistente social apresentaram muitas queixas com relação à mãe da criança, como privação de estímulos necessários ao desenvolvimento da criança e negligência (alimentação restrita, falta de estímulos, ausência de cuidados maternos, entre outros). A assistente social relatou que, na creche, as suspeitas começaram porque a criança ficava isolada, não possuía intenção comunicativa, não aceitava alimentos pastosos e sólidos e ficava em um canto, realizando movimentos repetitivos por até quatro horas seguidas. Quando o fato era relatado à mãe, esta praticamente ignorava as queixas da creche, relativizando os comportamentos da criança.

Com todos os dados apresentados e devido ao comportamento da criança foi solicitada uma avaliação de linguagem. A mãe foi convidada a comparecer à clínica, para a realização da anamnese, mas só compareceu após a terceira convocação e após a creche ter exigido sua presença para a manutenção da vaga da criança.

A mãe relata que, quando a criança tinha um ano de idade, depois de um incidente traumático em sua família (o pai da criança foi assassinado na presença da própria criança), esta não quis ir mais ao colo de ninguém; queria só ficar em casa, não gostava de ir a lugar algum e parou de comer. A mãe relatou não ter levado a criança a nenhum atendimento após o inci- 
dente, pois achava que a mesma não compreendia o ocorrido. Segundo a mãe, a gestação foi uma experiência agradável para os pais. A criança nasceu a termo e de parto normal. Não houve intercorrências no nascimento; porém, a mãe relata que o bebê não chorou ao nascer. $O$ peso da criança ao nascimento foi de $2985 \mathrm{~g}$ e comprimento de $46 \mathrm{~cm}$. A mãe não soube relatar o Apgar e a medida do crânio e disse ter realizado pré-natal a partir da segunda semana de gestação.

Relatou, ainda, que o pediatra considerava-o um bebê muito quieto. Esta percebeu que o filho poderia ter algum problema somente aos dois anos, quando reparou que este não falava como as outras crianças. Na época da anamnese, segundo a mãe, a criança estava magra porque apresentava quadro de anemia e estava em tratamento com sulfato ferroso, indicado por pediatra do posto do bairro onde moram. Segundo a mãe, a criança já passou por oito pediatras devido ao problema alimentar e já havia sofrido diversas internações por desidratação, mesmo antes da anemia. Indagada sobre a grande frequiência de desidratações e sobre a troca excessiva de pediatras, a mãe se limitava a sorrir.

Segundo a mãe, o bebê chorava muito nos dois primeiros meses, dormia em demasia, não respondia a estímulos auditivos e visuais; porém, ela o considerava em condições satisfatórias de saúde até que desenvolveu problemas alimentares. A criança não come alimentos sólidos e pastosos, somente aceita o leite. A mãe considera o filho uma criança afetuosa, mas que não sorri quando chegam pessoas conhecidas. Faz movimentos repetitivos quando está com sono, como ficar balançando a chupeta e não apresenta dificuldades para imitar. Em relação ao seu desenvolvimento, apresentou equilíbrio de pescoço aos quatro meses, virou aos quatro meses; agarrou objetos aos dois meses, sentou com apoio aos seis meses, sentou sem apoio aos sete meses, ficou em pé aos oito meses e andou com dois anos. Nota-se aqui uma incoerência no relato materno sobre desenvolvimento neuropsicomotor e de linguagem.

Ainda, segundo relato materno, com nove meses a criança falou "mama" e "dá" e puxava a pessoa quando queria alguma coisa. Não utiliza gestos até hoje para mostrar o que quer e a mãe concorda que o filho apresenta problemas de fala, embora afirme ser este o único problema da criança. A criança não inicia diálogos; dessa forma, chama atenção da mãe pedindo colo e erguendo os braços.

Para ela, ele entende o que os outros dizem, obedece a ordens simples, não apresenta fala peculiar, não utiliza sons especiais, apresenta fala sem significado e repete sons. Novamente, nota-se o relato incoerente, já que a própria mãe anteriormente declarou que o paciente não emitia sons e, em um segundo momento, afirmou que ele apresenta fala sem significado.

Quanto à escola, ele freqüentava a creche do bairro há apenas um mês. Na época da anamnese, a criança tomava várias medicações, sendo que a mãe desconhecia a indicação médica para tais medicamentos, afirmando que deviam ser indicados para a anemia. Segundo a mãe, a criança é acompanhada pelo pediatra a cada três meses, mas não soube relatar o nome do médico, nem o local de atendimento. Conforme relato, o pediatra da criança disse que ela não é autista.

Para a mãe, ele só tem problema de fala e alimentação e ela afirma não ter estimulado a fala porque não tinha tempo.
Segundo a mãe, seu filho é calmo e sua expectativa quanto ao tratamento fonaoudiológico é a de que ele comece a pedir as coisas.

De forma geral, durante toda anamnese, como já foi relatado, observaram-se algumas incoerências no relato da mãe, que apresentou falas contraditórias, demonstrando desconhecimento do quadro de seu filho e de todo o seu desenvolvimento, o que só veio corroborar os relatos da cuidadora e da assistente social da creche.

A avaliação fonoaudiológica consistiu, inicialmente, no levantamento da história da criança e de seu desenvolvimento. Em seguida, foram realizadas filmagens da criança em situações lúdicas diversas: sozinha, com as avaliadoras e com a mãe (três situações diferentes de filmagens). Foi também aplicado o protocolo de observação comportamental ${ }^{(15)} \mathrm{e}$, por último, foi realizada filmagem da criança no ambiente escolar (creche).

Após a análise das filmagens, foi preenchida, em conjunto com o Setor de Psicologia, a escala para autismo do DSM-IV $\mathrm{TR}^{(9)}$, para verificação dos sintomas apresentados pela criança relacionados ao autismo, sendo que a criança apresentou todos os sintomas relacionados.

Pela aplicação do protocolo de observação comportamental, foi observada ausência de habilidades dialógicas e comunicação intencional. Quanto às funções comunicativas, foram observadas as ações gestuais de solicitar brinquedo do seu interesse, tentativa de abrir a porta e protesto por meio nãoverbal. Não houve nenhuma forma de comunicação oral, nem vocalizações, nem balbucios, sendo que a criança permaneceu o tempo todo em silêncio e realizando movimentos repetitivos de balanceio com corpo e mãos. Quanto à compreensão verbal, não apresentou resposta à linguagem. Quanto os aspectos do desenvolvimento cognitivo, a criança manipulou um único objeto de modo repetitivo e persistente. Não apresentou condutas simbólicas, apenas sensório-motoras e manipulou objetos do seu interesse sem uma organização dos mesmos e sem dar funcionalidade. Não reagiu à fala e apresentou pouco contato visual.

Não apresentou nenhuma reação quanto à presença da mãe e das avaliadoras na sala. Foi realizada uma filmagem da interação entre mãe e filho e, nesta, solicitou-se que a mãe permanecesse sozinha com a criança na sala de terapia para observação do comportamento em sua presença, em uma situação de atividade lúdica. Observou-se interação restrita, já que a mãe não solicitava nenhuma atitude de comunicação (início ou manutenção) e, também, ausência de comportamento comunicativo por parte da criança.

A criança também foi filmada pelas terapeutas em ambiente escolar (creche), no momento de alimentação e interação com outras crianças. Esta visita à creche proporcionou um maior contato com as cuidadoras, as quais forneceram informações da rotina da criança, seu comportamento e a relação entre a mãe e a creche.

O relato da cuidadora, juntamente com a observação das terapeutas no ambiente escolar, evidenciou o comportamento autístico e a restrição alimentar. Observou-se grande dificuldade por parte das cuidadoras em alimentar e interagir com a criança, que rejeitava comida, o que, segundo a cuidadora, acontecia todos os dias. 
A assistente social da creche fez uma visita programada à casa da criança e constatou a situação de abandono da mesma, que fica o dia todo em um quarto escuro, dentro de um cercado infantil, sem cama ou berço apropriado. A casa não tem energia elétrica, nem geladeira e fogão. A mãe relata ter se desfeito dos móveis e utensílios domésticos por razões financeiras. A assistente social da creche argumentou que a mãe possuía renda suficiente para sua subsistência familiar e estava empregada há mais de 12 meses, não encontrando justificativas para um ambiente tão restrito de recursos. Esclareceu, ainda, à mãe sobre a denúncia que a creche faria da situação aos órgãos competentes. Frente às evidências de privação sensorial e negligência, foi realmente feita uma denúncia pela creche para o CRAMI (Centro Regional de Atenção aos Maus Tratos na Infância), que encaminhou a mesma ao Conselho Tutelar da cidade. Posteriormente, a queixa também foi encaminhada ao Ministério Público Federal (Vara da Infância e Adolescência).

Com os dados obtidos durante a avaliação fonoaudiológica, juntamente com a literatura, pôde-se afirmar que a criança apresenta um distúrbio de linguagem como parte de um quadro de transtorno global do desenvolvimento (características autísticas).

Foi indicado início imediato de terapia fonoaudiológica, inserção escolar adequada, juntamente com o encaminhamento para uma instituição especializada e levantada a necessidade de avaliações diagnósticas em Neurologia e Psicologia para investigação da hipótese de autismo primário ou secundário a uma possível privação sensorial de estímulos e de possíveis danos neurológicos, causados pela desnutrição.

Desse modo, a mãe foi orientada a respeito da importância do atendimento com uma equipe multidisciplinar, em uma instituição especializada em autismo; porém, esta se recusa a aderir ao tratamento dessa instituição, uma vez que seu filho somente apresenta problemas de fala.

A avaliação psicológica foi realizada pelo Setor de Psicologia da Clínica de Fonoaudiologia da FOB-USP. Segundo o parecer psicológico, a criança apresenta padrão de comportamento de apego do tipo inseguro frente às relações interpessoais e, desta forma, seus recursos para enfrentar novas situações revelam-se insuficientes, gerando alto nível de ansiedade e evidenciando falhas na organização e integração do ego, falhas estas que prejudicam as funções adaptativas.

Pela avaliação psicológica, ficou evidente, na criança, a distorção na cronologia, no ritmo e na sequiência das funções psicológicas envolvidas no desenvolvimento de aptidões sociais e de linguagem, não atingindo os padrões esperados para a sua idade e grupo cultural, especificamente quanto às habilidades sociais, responsabilidades, comunicação, domínio das atividades de vida prática, independência pessoal e autosuficiência. Seu repertório de interesses e atividades é restrito e a função simbólica, avaliada por meio do brincar, entre outras atividades, é pobre assim como a qualidade interacional e a comunicação não-verbal; manipula os objetos funcionalmente sem estabelecer padrão lúdico/simbólico dificultando as novas aprendizagens (jogos e brincadeiras). O emprego do corpo, muitas vezes, mostrou-se atípico com condutas incomuns para a idade. É uma criança com dificuldade no controle de suas funções corporais e de seus impulsos.
Por meio de entrevista psicológica específica e da escala de comportamento afetivo, a mãe caracteriza o filho como uma criança inibida frente ao ambiente social, devido ao episódio traumático presenciado por ele (morte do pai), mas com desenvolvimento igual a outras crianças de sua idade, exceto em relação à linguagem oral, minimizando as alterações comportamentais já referidas. Portanto, a percepção do filho está estreitamente relacionada ao psicodinamismo da mãe, isto é, à sua subjetividade e não à realidade em si.

O laudo psicológico foi de que a maioria das manifestações descritas é compatível ou com quadros, como aqueles decorrentes de privação biopsicosocial, transtorno reativo de apego ou o transtorno global do desenvolvimento (autismo) de baixo funcionamento cognitivo.

Desta forma, a partir da integração dos achados da avaliação psicológica com os dados referentes à avaliação fonoaudiológica e ao ambiente pré-escolar (creche), a criança e a mãe foram acompanhadas até o neuro-geneticista do Hospital de Reabilitação de Bauru (HRAC) para auxiliar no diagnóstico diferencial. A conclusão diagnóstica do profissional foi de autismo funcional e a conduta foi uma solicitação de ressonância magnética de encéfalo, a fim de estabelecer a natureza primária ou secundária (alteração do SNC) do distúrbio.

De qualquer forma, a conduta inicial para quadros desta natureza é a de englobar a organização, a estrutura do ambiente e a psicodinâmica da família, uma vez que as informações obtidas em outros âmbitos de vivência da criança apontaram veementemente graves falhas na provisão de estímulos adequados, importantes para o pleno desenvolvimento do potencial de qualquer criança, tenha ela ou não algum comprometimento orgânico.

A conduta psicológica, por fim, foi a de manutenção da criança na creche e acompanhamento especializado por equipe multiprofissional na forma de programas estruturados para crianças com necessidades especiais como aqueles oferecidos pelas instituições especializadas em autismo - sendo esta a mesma conduta já indicada ao final da avaliação fonoaudiológica.

A terapia fonoaudiológica teve início logo após o término de todo o processo de avaliação, sendo que a criança está em terapia fonoaudiológica na Clinica de Fonoaudiologia da FOBUSP, com freqüência de uma vez por semana, com sessões de uma hora de duração, já que a mãe relata não poder freqüentar a clínica com maior freqüência. São trabalhados, por meio de atividades lúdicas, os mecanismos de interação básicos, como: contato ocular, a troca de turnos, intencionalidade comunicativa, interesse por objetos e pelo outro. Em relação à linguagem, busca-se o início das vocalizações e comunicação por meios verbais, com intencionalidade. Para que tais objetivos fossem alcançados, foi criado um ambiente de interação das terapeutas com a criança, promovendo atividades nas quais um deles necessite do outro para a realização da atividade proposta. Para que também se criasse a percepção da atividade social e comunicativa, as terapeutas imitavam os movimentos estereotipados da criança, dando função e atribuindo um som ou significado ao mesmo.

Uma das estratégias foi a de colocar diversos objetos na frente da criança, fazendo uma demonstração da função dos 
mesmos associados a um som para que, frente aos estímulos oferecidos, a criança escolhesse o de sua preferência e, a partir daí, esse objeto fosse manipulado funcionalmente. Também, foram utilizadas atividades com músicas associadas a gestos, a fim de que a criança tivesse algum comportamento de imitação ou mesmo a demonstração de interesse pela música, gesticulando enquanto a música tocava e cessando os movimentos quando a música parava.

Devido às faltas regulares da mãe ao tratamento fonoaudiológico, pode-se dizer que a criança apresentou períodos de evolução, porém não de forma constante. No fim do primeiro semestre de intervenção, de acordo com informações obtidas por meio da creche, a criança foi diagnosticada com anemia profunda, sendo que a mãe recusou o tratamento pediátrico e, por esse motivo, a criança foi suspensa da creche. Dessa forma, nos meses subseqüentes, a criança passou a freqüentar uma nova creche. Foram obtidas informações por intermédio da diretora da nova creche a respeito da situação e esta informou que a mãe não comparece a creche todos os dias, sendo que as cuidadoras têm dificuldades em alimentar a criança. Foi realizada uma visita a esta nova creche, sendo observados comportamentos de auto-estimulação por parte da criança, ausência de interação com as outras crianças e rejeição de alimentos, isto é, o mesmo quadro observado na creche anterior. Foi discutido o caso com a diretora da creche e esta confirmou que a negligência continua ocorrendo.

Os resultados da intervenção fonoaudiológica, de acordo com os objetivos propostos já apresentados, foram os seguintes: a criança aumentou o tempo de contato ocular com as terapeutas, passou a aceitar o contato corporal e a demonstrar um maior interesse pelos objetos, permanecendo mais tempo em determinadas atividades, iniciando as vocalizações indiferenciadas em momentos de prazer e diminuindo os movimentos repetitivos. É importante ressaltar que o progresso terapêutico é visto de forma lenta, uma vez que não há o apoio familiar crucial para o desenvolvimento da criança, concluído a partir da negligência da mãe. Assim mesmo, certificando-se dos limites de uma criança autista que sofreu privação sensorial, esperavam-se evoluções mais significativas da criança no tratamento fonoaudiológico pelo período proposto (nove meses).

\section{DISCUSSÃO}

A criança em questão sofreu um trauma na primeira infância, privação de estímulos e apresenta características autísticas, enquadrando-se em todos os quesitos para autismo ${ }^{(9)}$. Existem relatos de casos de crianças em que o próprio quadro autístico era a causa do abandono ${ }^{(5)}$. Há também outros relatos nos quais o abandono foi causa dos comportamentos autísticos. Dessa forma, é importante questionar se a criança já nasceu com o quadro autístico e, frente a isso, sofreu a rejeição e negligência da mãe, sendo este um fator agravante do quadro, ou se adquiriu os comportamentos autísticos, secundários à privação de estímulos e trauma sofridos ${ }^{(6)}$.

De acordo com a literatura ${ }^{(1-2)}$, a aquisição de linguagem é um processo natural e esperado em crianças que vivem condições favoráveis. Assim, quaisquer fatores que tornem o ambiente adverso, como a privação de estímulos e mesmo a desnutrição durante a fase da aquisição, podem levar a um comprometimento no desenvolvimento da linguagem. Sabe-se, por meio dos diversos relatos deste estudo de caso, que a criança foi criada em um ambiente privado de estímulos, o que pode ter influenciado diretamente o seu desenvolvimento de linguagem. Além disso, pelos dados da literatura ${ }^{(3)}$, sabe-se que a interação de pais com filhos com deficiência de linguagem também pode ser afetada negativamente, levando ao abandono e sentimentos de negação. Como a interação com o outro é fundamental para o desenvolvimento normal da linguagem ${ }^{(4)}$, no caso aqui apresentado, tudo indica que a criança vive em um meio de interação restrito ao ambiente familiar, uma vez que - como o constatado pela assistente social da creche - a criança passava a maior parte do dia sozinha dentro de um cercado infantil e em um quarto escuro, sem alimentação adequada. Uma insuficiência de estimulações sensoriais, sociais e afetivas pode levar a um déficit global de desenvolvimento em casos mais severos ${ }^{(5)}$, como parece ter ocorrido neste estudo de caso.

Privações extremas na primeira infância podem resultar em comportamentos autísticos, que se caracterizam basicamente por déficits de interação social, linguagem e alterações de comportamento $^{(5-6)}$. A criança deste estudo de caso apresenta comportamentos extremamente característicos do quadro autístico, o que leva à reflexão sobre a possibilidade do caso se tratar um quadro de autismo primário, cujas manifestações foram agravadas devido à privação de estímulos sofrida ${ }^{(12)}$.

A apresentação de um caso como o aqui descrito justificase pelo fato dos fonoaudiólogos serem profissionais da área da saúde, que sempre estão em contato com crianças com alterações no desenvolvimento da linguagem e seus familiares. Alguns dos pontos que chamaram a atenção no comportamento da mãe da criança, nas alterações encontradas, no histórico do caso como um todo e nos relatos das creches e das cuidadoras, no caso aqui apresentado, podem servir de alerta para casos similares que estes profissionais possam vir a atender.

\section{COMENTÁRIOS FINAIS}

Conclui-se que, em casos como este, é necessária uma intervenção global, com a atuação de diversos profissionais da saúde e áreas afins, de forma a proporcionar à criança um bom desenvolvimento em todos os aspectos comprometidos. É fundamental a inserção dessas crianças em instituições que possibilitem uma atenção mais direcionada às suas dificuldades, assim como o encaminhamento destas famílias a serviços de apoio. Como em qualquer programa de intervenção, o apoio da família a e sua total dedicação são fatores determinantes no desenvolvimento da criança e nas suas evoluções ao longo do processo terapêutico. Dessa forma, torna-se claro neste caso que há diversos pontos que influenciam a evolução lenta da criança na terapia fonoaudiológica e nas demais áreas comprometidas, como o crescimento corporal, o amadurecimento de certas respostas já esperadas para a sua idade, independentemente do quadro autístico. Não se sabe até que ponto a manutenção das características autísticas e os comportamentos apresentados pela criança estão sendo determinados pela privação sensorial que esta sofre, ou mesmo pela severidade do quadro em autístico em questão. 
É obrigação social do fonoaudiólogo como profissional da saúde, não somente atuar em questões referentes à comunicação, mas intervir mais amplamente, tendo por objetivo o desenvolvimento global da criança. É importante conhecer os diversos ambientes que a criança freqüenta, assim como os demais profissionais que atuam com a criança e com a família, propondo estratégias que viabilizem uma maior adequação social desta ao ambiente em que está inserida.

\begin{abstract}
The aim of this study was to report the case of a child with autistic characteristics, who was deprived from stimulus due to maternal negligence. A male two-year-old child was assessed and followed by the team of a University's Speech and Language Pathology (SLP) Clinic. He was diagnosed with language disorder as part of a global development disorder, and referred to language therapy. Due to the fact that the child had nutritional and global development deficits, he was also referred to medical care and to an institution specialized in autistic patients. Throughout the SLP intervention process, the child showed increase of eye contact, acceptance of body contact, more interest in objects, beginning of vocalizations and decrease of the repetitive movements. However, the therapeutic results were limited by the problematic setting. Intervention was carried out with collaboration from the daycare facilities that the child attended and also from other assistance organs, since there was a formal denunciation regarding the mother's negligence. This case report aims to show that, in severe cases, a global intervention, with involvement of several health professionals, is necessary to provide the development of all the impaired aspects. Family support is fundamental to the child's development, thus, it is not possible to state whether the subject's behaviors were determined by the deprivation of sensory stimulus or by the severity of the autism. Therefore, investigation and intervention work must be continued.
\end{abstract}

Keywords: Autistic disorder; Sensory deprivation; Child abuse; Language development disorders

\section{REFERÊNCIAS}

1. Aguado G. Dimensões perceptivas, sociais, funcionais e comunicativas do desenvolvimento da linguagem. In: Chevrie-Muller C, Narbona J. A linguagem da criança: aspectos normais e patológicos. 2a ed. Porto Alegre: Artmed; 2005. p. 71-87.

2. Mogford K, Bishop D. Desenvolvimento da linguagem em condições normais. In: Bishop D, Mogford K, organizadores. Desenvolvimento da linguagem em circunstâncias excepcionais. Rio de Janeiro: Revinter; 2002. p.1-26.

3. Law J. Fatores associados a deficiência de linguagem. In: Law J. Distúrbios da linguagem na criança. Rio de Janeiro: Revinter; 2001. p. 43-9.

4. Perissinoto J. Diagnóstico de linguagem em crianças com transtornos do espectro autistico. In: Ferreira LP, Befi-Lopes DM, Limongi SCO, organizadores. Tratado de fonoaudiologia. São Paulo: Editora Roca; 2004. p. $933-40$.

5. Domenech E. Distúrbios afetivos e patologia da linguagem. In: ChevrieMuller C, Narbona J. A linguagem da criança: aspectos normais e patológicos. 2a ed. Porto Alegre: Artmed; 2005. p. 458-72.

6. Skuse DH. Privações extremas na primeira infância. In: Bishop D, Mogford K. Desenvolvimento da linguagem em circunstâncias excepcionais. Rio de Janeiro: Revinter; 2002. p. 27-50.

7. Noguchi MS, Assis SG, Malaquias JV. Ocorrência de maus-tratos em crianças: formação e possibilidade de ação dos fonoaudiólogos. Prófono. 2006;18(1):41-8.
8. Ballone GJ. Crianças adotadas e de orfanato [Internet]. [revisado 2004; citado 2006 Out 18]. Disponível em: virtualpsy.locaweb.com.br/index. php?art $=52 \& \sec =19$.

9. Associação Americana de Psiquiatria. Manual Diagnóstico e Estatístico de Transtornos Mentais. (DSM-IV-TR). 4a ed. Porto Alegre: Artes Médicas; 2002.

10. Perissinoto J, organizador. Conhecimentos essenciais para atender bem a criança com autismo. São José dos Campos: Pulso Editorial; c2003. $65 \mathrm{p}$.

11. Fernandes FDM, Teles P. Linguagem nos transtornos do espetro autístico. Rev Soc Bras Fonoaudiol. 2005;10(4):207-10.

12. Rapin I. Distúrbios da comunicação no autismo infantil. In: ChevrieMuller C, Narbona J. A linguagem da criança: aspectos normais e patológicos. 2a ed. Porto Alegre: Artmed; 2005. p. 439-57.

13. Fernandes FDM. Terapia de linguagem em crianças com transtornos do espectro autístico. In: Ferreira LP, Befi-Lopes DM, Limongi SCO, organizadores. Tratado de fonoaudiologia. São Paulo: Editora Roca; 2004. p. 941-53.

14. Lampréia C. Avaliações quantitativa e qualitativa de um menino autista: uma análise crítica. Psicol Estud. 2003;8(1):57-65.

15. Zorzi JL, Hage SRV. PROC - Protocolo de observação comportamental: avaliação de linguagem e aspectos cognitivos infantis. São José dos Campos: Pulso Editorial; c2004. 